\title{
GESTÃO DA QUALIDADE NA PREVENÇÃO DOS DESPERDÍCIOS EM CANTEIRO DE OBRAS DA CONSTRUÇÃO CIVIL
}

\author{
QUALITY MANAGEMENT IN THE PREVENTION OF WASTE IN A CIVIL IN CONSTRUCTION \\ SITE \\ $\underline{\text { Thiago Almeida Boeriz }}^{1^{*}}, \& \underline{\text { Manoel Goncales Filho }}^{2}$ \\ ${ }^{12}$ Escola Superior de Agricultura "Luiz de Queiroz". Universidade de São Paulo-PECEGE-ESALQ-USP \\ 1* thiago.almeida.boeriz@gmail.com ${ }^{2}$ manoel.goncales01@ fatec.sp.gov.br
}

\section{ARTIGO INFO.}

\section{Recebido em: 23.06.2021}

Aprovado em: 12.07.2021

Disponibilizado em: 26.07.2021

\section{Palavras-chave:}

Lean; Construction; Thinking; Construção Enxuta; Pensamento Enxuto.

\section{KEYWORDS:}

Lean; Construction, Thinking; Lean Construction; Lean Thinking.

\section{*Autor Correspondente: Boeriz, T. A.}

\section{RESUMO}

A construção civil é um dos setores que mais contribui para economia do Brasil, visto que nesses últimos anos, perante o impacto que vem sofrendo outros setores devido aos problemas sanitários vivenciados (COVID-19), a construção foi um dos pilares que suportaram o Produto Interno Bruto (PIB) do país. A aplicação da filosofia "Lean Construction", originados pelo Sistema de Produção Toyota (STP), traz como principal objetivo a possibilidade de redução dos desperdícios ocasionados pelos processos produtivos das indústrias, e para os processos da construção civil, reconhecidos como um dos maiores geradores de resíduos do país, não é diferente. Esta pesquisa possui uma abordagem qualitativa e o procedimento técnico utilizado foi o estudo de casos. Os resultados identificados são a falta de uma gestão mais bem estruturada e sistematizada dentro do canteiro de obras; oportunidade de fomentar ganhos financeiros; falta do conhecimento sobre à filosofia Lean; falta de planejamento na gestão dos materiais e transporte; falta de treinamento dos operários; falta de visão sistêmica de produção, excesso de estoque e; movimentos / transportes desnecessários para a execução das atividades A contribuição ocorrerá por meio do embasamento e filosofia Lean, sendo apresentado as construtoras, uma nova proposta de trabalho para gerar maior produtividade alinhado a redução de custos e desperdícios gerais, assim alcançando melhores resultados, como consequência terão suas atividades com maior qualidade e preços mais competitivos no mercado.

\begin{abstract}
Civil construction is one of the sectors that contributes the most to Brazil's economy, since in recent years, in view of the impact that other sectors have been suffering due to the sanitary problems experienced (COVID-19), construction was one of the pillars that supported the country's Gross Domestic Product (GDP). The application of the "Lean Construction" philosophy, originated by the Toyota Production System (STP), brings as its main objective the possibility of reducing the waste caused by the industries' productive processes, and for the civil construction processes, recognized as one of the biggest waste generators in the country, it is no different. This research has a qualitative approach and the technical procedure used was the case study. The results identified are the lack of a better structured and systematized management within the construction site; opportunity to foster financial gains; lack of knowledge about the Lean philosophy; lack of planning in the management of materials and transportation; lack of training of workers; lack of systemic vision of production, excess inventory and The contribution will occur through the foundation and Lean philosophy, being presented to the construction companies, a new work proposal to generate greater productivity aligned to reduce costs and general waste, thus achieving better results, and as a result will have their activities with higher quality and more competitive prices in the market.
\end{abstract}




\section{INTRODUÇÃO}

Com base nas informações da Indústria da Construção Civil [CBIC] (2020), nota-se a importância do setor da construção civil na economia do país fundamentado pelo resultado do Produto Interno Bruto [PIB] no terceiro trimestre de 2019, com expansão de 0,6\% em relação ao segundo trimestre, sinalizando um crescimento de 1,2\% da economia brasileira em relação ao mesmo trimestre de 2018. Todavia, diferentemente do ano atípico de 2020, na qual houve uma queda de 2,5\% devido a pandemia de COVID-19, devido a suspenção das obras em algumas localidades no país.

Melo (2012) relata que a construção civil é um setor importante para a economia de qualquer país, pois contribui de forma relevante para fomentar novos postos de trabalho, seja direta ou indiretamente. Segundo o autor, em contrapartida, também é uma das atividades que mais geram volume de resíduos por consequência de desperdícios ocasionados no canteiro de obra.

De acordo com Grohmann (1998), esses desperdícios podem ser apontados como a falta de mão de obra qualificada, além da ausência de orientações técnicas de construção, pois por meio de um canteiro de obra organizado e planejado é possível reduzir os desperdícios de forma geral, na qual consequentemente irá aumentar a produtividade.

Para Koskela (1992), o "Lean Construction" surge para atender a necessidade de execução das atividades operacionais visando obter uma construção mais enxuta (sem desperdícios), cuja filosofia pode ser adotada do Sistema Toyota de Produção (STP) pelo setor da construção civil.

O Sistema Toyota de Produção (STP) tem como principal objetivo aumentar a eficiência da produção por meio da eliminação consistente de desperdícios (Shingo, 1996) com base no conceito dos 4 P's (Filosofia; Processo; Pessoas e Parceiros e; Resolução de Problemas), e pelos 14 princípios, sendo: 1) Basear suas decisões de gestão em uma filosofia de longo prazo, mesmo à custa de objetivos financeiros de curto prazo; 2) Criar fluxo de processo contínuo para trazer problemas para superfície; 3) Usar sistema puxado para evitar a produção superior; 4) Nivelar o trabalho (Heijunka); 5) Construir uma cultura de parar para estudar problemas, para obter qualidade direita na primeira vez; 6) Tarefas padronizadas são a fundação para melhorias contínuas e alocação de empregado; 7) Utilizar o controle visual para que nenhum problema esteja oculto; 8) Utilizar tecnologia somente se for confiável e que sirva as suas pessoas e seu processo; 9) Desenvolver / capacitar os líderes para o trabalho, filosofia para ensinar outros colaboradores; 10) Criar e desenvolver equipes excepcionais que seguem a filosofia da empresa; 11) Respeitar a rede externa de parceiros e fornecedores, desafiando-os e ajudandoos a melhorar seus processos; 12) Compreender melhor a situação em campo (Genchi Genbtsu); 13) Tomar decisões lentamente por consenso, considerando todas as opções, e implementá-las rapidamente; 14) Tornara organização de aprendizagem pela reflexão (Hansei) e viabilizar melhorias contínuas (KAIZEN).

O engenheiro de produção da Toyota, Taiichi Ohno, relata oito tipos de perdas relacionada ao "Lean Construction" a fim de se eliminarem (Moden, 1984), sendo: 1) Perdas pela superprodução; 2) Perdas por tempo de espera; 3) Perdas com transportes desnecessários; 4) Perdas do processamento; 5) Perdas por estoques; 6) Perdas por movimentos; 7) Perdas de produtos com defeitos; 8) Perdas por potencial humano; 

construção civil. Brazilian Journal of Production Engineering, 7(3), 71-84.

Segundo Womack et al. (2004), Pensamento Enxuto, conhecido como “Lean Thinking” é uma forma de especificar valor, alinhar na melhor sequência as ações que criam valor, realizar atividades sem interrupção toda vez que alguém às solicita, e executá-las de forma cada vez mais eficiente e eficaz.

Para alinhar a melhor forma de criar valor, Piatkowski (2004) e Zuchelli (2018) apresentam cinco ferramentas e relatam os objetivos que apoiam a qualidade e produtividade por meio dos processos-chave de negócio, que são: 1) Programa 5S: diminuição do ambiente de trabalho e aumento da qualidade e produtividade; 2) Trabalho Padronizado: diminuir o tempo do clico, diminuição de defeitos e de custos; 3) Mapeamento do Fluxo de Valor: diminuição de desperdícios, menor tempo de ciclo e redução de custo; 4) Controle Visual: disponibilidade em tempo real das informações, melhor engajamento, promover a melhoria continua, maior produtividade e promover o Just In Time; 5) Total Productive Maintenance: melhorar a flexibilidade, qualidade, produtividade e redução de custos;

A literatura e as referências citadas estimulam e desafiam buscar e compreender como aplicar os conceitos do "Lean Construction" por meio do "Lean Thinking" em canteiro de obras de setor específico como o da construção civil. O objetivo do trabalho, é obter informações dos problemas cotidianos de perdas geradas pelo setor para que possa sequencialmente apresentar um plano de trabalho para melhoria através da metodologia "Lean" juntamente com o apoio do questionário de pesquisa está em realizar uma pesquisa bibliográfica que apoie o gerenciamento da qualidade para diminuir ao máximo os desperdícios no ciclo do produto e/ou projeto, aumentar a produtividade, tornar o processo mais sustentável e gerar valor ao cliente do setor de construção civil.

\section{MATERIAL E MÉTODOS}

Pesquisas científicas iniciam-se com uma questão e objetivos de pesquisa, que podem resultar de experiências do próprio pesquisador ou de achados na literatura, e trazer contribuições ao campo do conhecimento (Gabriel, 2014). O conhecimento científico diferencia-se de outros conhecimentos por utilizar-se de levantamentos e análises metódicas e sistemáticas, sempre bem estruturadas, e que podem ser verificadas e comprovadas (Raupp e Beuren, 2008; Gerhardt e Souza, 2009; Zanella, 2011).

Nessa seção será descrito o aspecto metodológico adotado na pesquisa, quanto à̀ classificação geral, natureza, métodos de pesquisa, objetivos de pesquisa, procedimento técnico, técnica de coleta e análise dos dados e a caracterização da empresa investigada - unidade de análise e amostra.

A pesquisa conduzida é de natureza aplicada na qual possui o objetivo de suscitar novos conhecimentos para aplicabilidade de práticas dirigidas a soluções de problemas científicos, envolvendo verdades e interesses locais (Prodanov e Freitas, 2013).

Adotou-se o método comparativo para que possa ser investigado e analisados os dados, apontando suas diferenças e até mesmo similaridades quando houver. O método comparativo ocupa-se da explicação dos fenômenos e permite analisar o dado concreto, deduzindo desse "os elementos constantes, abstratos e gerais (Lakatos e Marconi, 2007).

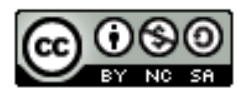



construção civil. Brazilian Journal of Production Engineering, 7(3), 71-84.

O método comparativo procede pela investigação de indivíduos, classes, fenômenos ou fatos, com vistas a ressaltar as diferenças e as similaridades entre eles. Sua ampla utilização nas ciências sociais deve-se ao fato de possibilitar o estudo comparativo de grandes grupamentos sociais, separados pelo espaço e tempo (Gil, 2008).

Para Gil (2002), a pesquisa exploratória proporciona maior familiaridade com o problema a ser investigado, sendo que na maioria dos casos assume a forma de pesquisa bibliográfica ou de estudo de casos, possível de ser desenvolvida com base em material já elaborado, constituído principalmente por livros e artigos científicos (Gil, 2002).

Para o levantamento dos documentos que compõem o referencial teórico para a pesquisa bibliográfica utilizou-se das bases de dados do (i) Google acadêmico; (ii) Portal de periódicos da CAPES e; (iii) banco de teses e dissertações da Esalq-USP; (iv) ScienceResearch.com;(v) Science.gov; (vi) Biblioteca Digital Brasileira de Teses e Dissertações (BDTD). As palavraschave utilizadas foram no idioma inglês e português, e considerou-se inclusive às palavras sobrepostas (i) Lean; (ii) Construction; (iii) Lean Construction; (iv) Thinking; (vi) Lean Thinking; (vii) Construção Enxuta; (viii) Pensamento Enxuto;

Para coletar os dados à campo, será utilizado de questionário preestabelecido, disponibilizado por meio do Apêndice A, com perguntas abertas que facilitam as entrevistas semiestruturadas, por possuir como característica, questionamentos que são apoiados em teorias e proposições identificadas na literatura, e que se relacionam ao tema principal desta pesquisa (Triviños, 1987).

Gil (2008), relata que sob o ponto de vista da abordagem do problema, a pesquisa pode ser qualitativa e considera que há uma relação dinâmica entre o mundo real e o sujeito, isto é, um vínculo indissociável entre o mundo objetivo e a subjetividade do sujeito que não pode ser apenas traduzido em números. Segundo o autor, a interpretação dos fenômenos e a atribuição de significados são básicas no processo de pesquisa qualitativa. $\mathrm{O}$ autor menciona que este tipo de pesquisa não requer o uso de método e técnicas estatísticas. Conforme o autor, o ambiente natural é a fonte direta para coleta de dados e o pesquisador é o instrumento-chave.

O procedimento técnico a ser utilizado é o estudo de casos para coletar os dados à campo e analisá-los por meio de uma forma mais profunda com base na literatura. Segundo Gil (2010) o estudo de casos, consiste no estudo profundo e exaustivo de um ou mais objetos, de maneira que permita seu amplo e detalhado conhecimento.

Todavia, previamente a aplicação do questionário e entrevistas será feito o teste piloto (préteste) para aprimorá-los. Essa consideração pode facilitar ao pesquisador a determinação de unidades de análise, reduzir o tempo de respostas, e a supressão das questões redundantes ou mal formuladas (Miguel, 2007).

A primeira unidade de análise, é uma empresa de médio porte, nacional, atuante da construção civil em obras verticais e horizontais, com especialidade na execução dos projetos fornecidos pelas incorporadoras e construtoras, por meio do fornecimento de mão de obra especializada para execução de atividades de infraestrutura, superestrutura e serviços gerais.

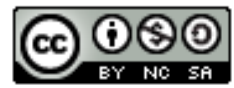



construção civil. Brazilian Journal of Production Engineering, 7(3), 71-84.

A segunda unidade de análise, é uma empresa de grande porte, nacional, atuante da construção civil em obras verticais e horizontais, com especialidade na incorporação e construção, executando projetos de obras verticais na capital de São Paulo, a empresa realiza produtos de médio e alto padrão.

A terceira unidade de análise, é uma empresa nacional de grande porte, atuante da construção civil com foco em obras verticais, tanto na capital São Paulo como no interior paulista, a empresa produz produtos de médio padrão e linha econômica, e promove a incorporação e construção, como o caso da minha casa minha vida (MCMV), que é um programa de habitação federal, no auxilio junto as pessoas de baixa renda na obtenção da casa própria.

Tabela 1. Apresenta um consolidado do perfil das empresas do estudo de casos.

\begin{tabular}{ccccccc}
\hline Empresa & $\begin{array}{c}\text { Setor de } \\
\text { atuação }\end{array}$ & $\begin{array}{c}\text { Tempo de } \\
\text { experiência no } \\
\text { mercado }\end{array}$ & Região & Especialização & Porte & $\begin{array}{c}\text { Quantidade de } \\
\text { funcionários }\end{array}$ \\
\hline A & $\begin{array}{c}\text { Construção } \\
\text { Civil }\end{array}$ & 22 & São Paulo & $\begin{array}{c}\text { Construtora especializada } \\
\text { com mão de obra de } \\
\text { infraestrutura, superestrutura } \\
\text { e serviços gerais. }\end{array}$ & $\begin{array}{c}\text { Médio } \\
\text { Porte }\end{array}$ & 360 \\
\hline B & $\begin{array}{c}\text { Construção } \\
\text { Civil }\end{array}$ & 47 & São Paulo & Incorporadora e Construtora & Grande & 520 \\
\hline C & $\begin{array}{c}\text { Construção } \\
\text { Civil }\end{array}$ & 35 & São Paulo & Incorporadora e Construtora & Grande & 400 \\
\hline
\end{tabular}

Fonte: Autores (2021).

A amostra dos entrevistados consiste em quatro respondentes, na qual serão abordados um (i) engenheiro residente e; (ii) diretor da construtora no fornecimento da mão de obra especializada; (iii) um diretor da incorporadora e construtora e (iv) um coordenador da incorporadora e construtora. O Tabela 2 apresenta o perfil dos respondentes.

Tabela 2. Perfil dos respondentes.

\begin{tabular}{lcccc}
\hline Nome & Entrevistado & $\begin{array}{c}\text { Tempo de } \\
\text { Empresa }\end{array}$ & Tempo de Experiência & Formação Acadêmica \\
\hline Entrevistado 1 & Engenheiro Residente & 3 meses & 17 anos & Bacharel em Engenharia Civil \\
\hline Entrevistado 2 & Diretor & 8 & 31 & Bacharel em Engenharia Civil \\
\hline Entrevistado 3 & Coordenador & 9 & 39 & Bacharel em Engenharia Civil \\
\hline Entrevistado 4 & Diretor Geral & 22 & 30 & $2^{\circ}$ Grau completo \\
\hline
\end{tabular}

Fonte: Autores (2021).

Todos os entrevistados possuem boa experiência na construção civil, especificamente na atuação em canteiro de obras, o que favorece e contribui com os resultados desta pesquisa.

Nenhum dos entrevistados possuem especializações na área de formação, mas os engenheiros e a coordenação dispõem de graduação na área. Todavia, os níveis de experiência variam entre 17 anos e 39 anos de atuação no setor, o que demostra um nível de contribuição importante para o trabalho.

Observa-se que o entrevistado com maior experiência, atua como Diretor de uma construtora, ou seja, em uma empresa de mão de obra qualificada na prestação de serviços de construção civil. O segundo integrante das entrevistas com mais experiência é um dos engenheiros que tem 17 anos de experiência e está diretamente ligado às obras. Desse modo, após definir a estrutura conceitual teórica por meio das bases de dados e das palavras-chave, planejou-se os casos -

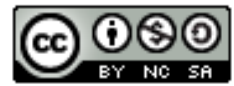



construção civil. Brazilian Journal of Production Engineering, 7(3), 71-84.

unidades de análise, definiu-se as amostras dos entrevistados, conduziu-se o teste piloto, coletou-se e analisou-se os dados e, discutiu-se os resultados do estudo de casos com as implicações teóricas.

\section{RESULTADOS E DISCUSSÃO}

Com base na literatura foi possível identificar as contribuições dos autores para uma análise sobre o "Lean Construction" quanto a aplicação dos conceitos e ferramentas para a gestão da qualidade na redução de desperdícios em canteiro de obras do setor da construção civil.

O levantamento de dados e informações feitas em campo com base na experiência prática dos profissionais do setor da construção civil, sobre às ferramentas da qualidade defendidas pela filosofia "Lean Construction", possibilitou realizar uma comparação com à literatura.

Contudo, a partir do Tabela 3 foram apresentadas as implicações teóricas principais, de modo abrangente e relevante, do que foi utilizado da revisão teórica no estudo de caso e nos resultados desta pesquisa. Todavia, na sequência foram detalhadas as contribuições trabalhadas pelos autores, comparativamente aos achados das entrevistas de campo do estudo de caso desta pesquisa.

Tabela 3. Aspectos principais aplicados nos resultados da pesquisa.

\begin{tabular}{|c|c|c|}
\hline $\begin{array}{l}\text { Categoria Principal A } \\
\text { Ser Analisada }\end{array}$ & Contribuições Da Literatura & Autores \\
\hline $\begin{array}{l}\text { Aplicação de Gestão da } \\
\text { Qualidade em canteiro } \\
\text { de obras }\end{array}$ & $\begin{array}{l}\text { Conceitos e ferramentas que apoiam a qualidade e produtividade das } \\
\text { atividades }\end{array}$ & Piatkowski (2004) \\
\hline Planejamento & $\begin{array}{l}\text { Para diminuir os desperdícios no ciclo do produto e/ou projeto e gerar } \\
\text { valor ao cliente }\end{array}$ & Piatkowski (2004) \\
\hline $\begin{array}{l}\text { Conhecimento sobre a } \\
\text { filosofia "Lean" }\end{array}$ & Execução das atividades operacionais sem desperdícios. & Koskela (2004) \\
\hline $\begin{array}{l}\text { Implementar a filosofia } \\
\text { "Lean" 4P's }\end{array}$ & $\begin{array}{c}\text { Philosophy; Processos; Pessoas / Parceiros e Problemas (solução de } \\
\text { problemas) }\end{array}$ & Shingo (1996) \\
\hline $\begin{array}{l}\text { Implementar a filosofia } \\
\text { "Lean" } 14 \text { princípios do } \\
\text { STP }\end{array}$ & $\begin{array}{l}\text { 1) Longo prazo; 2) Criar fluxo de processo contínuo; 3) Usar sistema } \\
\text { puxado; 4) Nivelar o trabalho; 5) Construir uma cultura de parar para } \\
\text { estudar problemas; 6) Criar padrão; 7) Utilizar o controle visual; 8) } \\
\text { Utilizar tecnologia especializada; 9) Desenvolver / capacitar os líderes } \\
\text { e operadores; 10) Criar e desenvolver equipes excepcionais que } \\
\text { seguem a filosofia; 11) Desenvolver parceiros e fornecedores; 12) } \\
\text { Compreender melhor a situação em campo; 13) Tomar decisões por } \\
\text { consenso; 14) Busca da melhorias contínua. }\end{array}$ & Shingo (1996) \\
\hline Desperdícios & $\begin{array}{l}\text { Desperdícios de Materiais; falta de mão de obra qualificada; ausência } \\
\text { de orientações técnicas; canteiro de obra organizado e planejado; } \\
\text { superprodução; tempo de espera; transportes desnecessários; } \\
\text { processamento; estoques; movimentos; defeitos e; potencial humano. }\end{array}$ & $\begin{array}{c}\text { Costa (2018); } \\
\text { Piatkowski (2004). }\end{array}$ \\
\hline $\begin{array}{l}\text { Especificar valor ao } \\
\text { cliente }\end{array}$ & $\begin{array}{l}\text { Implementar ferramentas: 1) Programa 5S; 2) Trabalho Padronizado; } \\
\text { 4) Controle Visual; 5) Just In Time; 6) Total Productive Maintenance. }\end{array}$ & $\begin{array}{c}\text { Costa (2018); } \\
\text { Piatkowski (2004). }\end{array}$ \\
\hline
\end{tabular}
Fonte: Autores (2021).

$\mathrm{Na}$ prática foi constatado que tanto a revisão da literatura, pré-teste do questionário, e às entrevistas realizadas, embasaram a obtenção dos resultados desta pesquisa, e os entrevistados contribuíram para que os dados levantados fossem possíveis de serem analisados.

Foi identificado junto aos entrevistados 1 e 2, que a construtora A não possui nenhum modelo de aplicação de gestão de qualidade, os processos não atendem às expectativas dos seus gestores para maior eficiência no processo produtivo, qualidade e, consequentemente, diminuição das perdas ocasionadas na obra. Além disso, não possui nenhuma ferramenta específica para o

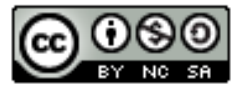



construção civil. Brazilian Journal of Production Engineering, 7(3), 71-84.

controle de produtividade e qualidade das atividades, faz apenas uso do MS Project (Software de gestão para controle das atividades) com apoio de planilhas de Excel. Nesse ponto, a construtora, está demonstrando total vulnerabilidade quanto a gestão de suas obras, na qual foi presenciado, quando feito as entrevistas no canteiro de obras, a desorganização no canteiro e até mesmo durante apresentação das informações para a pesquisa.

Os respondentes 1 e 2 mencionam que a construtora não faz uso desse tipo de gerenciamento, ou seja, o cliente é quem propõe a forma que será feito, desde o planejamento das atividades a contratação de materiais e cronograma, uma vez que toda as decisões gerenciais no canteiro de obras são repassadas pelos clientes (incorporadoras e/ou construtoras). O controle de produtividade é feito conforme elaboração de cronograma de obra que busca atingir os resultados por meio das metas quantitativas a serem atingidas mensalmente. Quando as metas estão fora do contexto do alcance, é sinalizado e apresentado as dificuldades que podem comprometer a entrega na data solicitada, ocasião em que é informado e realizado um plano de ação para correção do desvio ocasionado.

Por não haver um controle de gestão da produção, é identificado um processo produtivo deficiente, o que gera prejuízos, principalmente a produção mensal, correndo o risco de não faturar o suficiente para o pagamento dos custos fixos e variáveis que obtém ao mobilizar a equipe para atendimento das demandas apresentadas pelo cliente. Os entrevistados 1 e 2 , informam que não possuem uma ferramenta eficiente para gestão e controle de materiais, mas que é feito o controle de entrada, armazenamento e saída, realizados pelo Excel. O planejamento parte da sinalização do mestre de obras no momento que se reúne com a equipe para falar sobre o planejamento mensal. Foi relatado por ambos os respondentes que já ocorreram atrasos de cronograma devido ao prazo curto para compra dos materiais, o que acarretaram postergações das atividades e atrasos da obra como um todo.

A construtora faz uso do formulário FVS (Ficha de Verificação de Serviços), como apoio à sua produção e qualidade. Esse formulário, é elaborado com base nas exigências internas de planejamento feito pelos coordenadores e diretores com base na norma ABNT (Associação Brasileira de Normas Técnicas) muito utilizadas ano setor da construção civil. Nesse formulário existe o passo a passo para acompanhamento e validação das atividades, com isso, o engenheiro faz toda a verificação e liberações dos serviços. A ABNT é uma entidade que corrobora com as normatizações em todo país, na qual seu objetivo é estudar e propor formas de sistematizar processos, tanto na construção civil como nos demais setores. Outra ficha apresentada com base nos parâmetros de atendimento ao planejamento, controle e qualidade da empresa, é o formulário FVM (Ficha de Verificação de Materiais).

É relatado pelos entrevistados, que o FVM tem como finalidade fazer aferição e até mesmo o ensaio para análise de qualidade dos materiais, envolvendo o planejamento e controle mais assertivo dos materiais quanto à sua qualidade. Para esse caso, a falta de planejamento dos materiais, acaba ocasionando o desperdício de excesso de materiais dentro do canteiro de obras e, em outros casos, ocorrem, inclusive, à falta de materiais, com isso, a gestão mostra uma oportunidade de melhorar o processo produtivo. $\mathrm{O}$ excesso dos materiais gera outro ponto a ser considerado, a vulnerabilidade de se deteriorar, sendo esse é um desperdício considerado de 

construção civil. Brazilian Journal of Production Engineering, 7(3), 71-84.

difícil justificativa, como por exemplo, um palete de blocos que fica muitas vezes acessível por todos os operadores no canteiro de obras, algumas vezes são utilizados por outras atividades que não é de fato sua finalidade, gerando no final processo produtivo acréscimo às compras. As perdas / desperdícios por movimentos, foi outro item apontado com preocupação, pois é elaborado um "layout" de como será o canteiro de obras, desde a locação dos materiais juntamente com o abastecimento.

Ambos os entrevistados, apontam que mesmo realizando um estudo de como será o "layout" do canteiro de obras, algumas vezes é necessário fazer as alterações dos materiais, pelo fato de não ocorrer da forma que planejaram, o que ocasiona movimentos desnecessários dentro do canteiro. Com base desse desperdício, ocorrem perdas / desperdícios por tempo de espera, ou seja, quando é feita a movimentação desse material, a equipe de produção tem que aguardar a resolução do problema para ser abastecido. Outra questão apontada, é a perda / desperdício do potencial humano, na qual identificou-se que o operário não tem qualificação suficiente para executar a atividade. $\mathrm{O}$ entrevistado exemplifica que qualificação de um pedreiro para elevação de paredes de alvenaria, que tem dificuldades para compreender o projeto de produção, consequentemente não tem a percepção do alinhamento e prumo. Nesse caso, é necessário a demolição da parede gerando desperdício de materiais (blocos e argamassa) e produção, comprometendo à data final de entrega da obra.

Quanto aos custos gerados pelos desperdícios e retrabalhos, foi mencionado que os custos iniciais do projeto da obra, não atendia o planejado pela diretoria, e que sempre há necessidade de um investimento maior para finalização da obra. O entrevistado 1 informa que não tem conhecimento sobre às ferramentas e conceitos da filosofia Lean. Entretanto tem conhecimento da sua existência, e relata que nunca trabalhou em construtoras que fizessem a aplicação da filosofia e das ferramentas Lean nesses 17 anos de sua experiência profissional. Em contrapartida, o entrevistado 2, da mesma construtora, além de não conhecer sobre o Lean, aponta que nunca escutou sobre a filosofia e suas ferramentas enxutas, tão pouco no seu círculo de relacionamentos ou com outros diretores de outras construtoras.

O entrevistado 3 informa que a construtora B possui um processo de gestão da qualidade para gerenciamento, embasado nas referências da ISO (International Organization for Standardization). Outra ferramenta utilizada pela construtora para a gestão dos seus processos é conhecida como Organização Internacional de Normalização e PBQP-H (Programa Brasileiro da Qualidade e Produtividade do Habitat), ferramenta utilizada também pelo governo federal para medir dois pontos no setor da construção civil, sendo: a melhoria de qualidade do habitat e modernização produtiva. O entrevistado complementa que o "Lean Construction" não é adotado pela construtora, mas informa que existe um planejamento de curto, médio e longo prazos, na qual é feito o acompanhamento somente pelo MS Project. Quanto ao controle sobre produtividade e qualidade, é realizado por meio de controles semanais junto aos fornecedores, realizando reuniões pré-determinadas e agendadas com todos os envolvidos nas atividades a serem executadas. Todavia, as metas semanais, são estabelecidas pelo departamento de planejamento, com base em referências do mercado e dos projetos concluídos, possibilitando uma visão sistêmica sobre o controle das atividades.

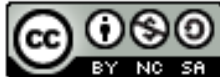



construção civil. Brazilian Journal of Production Engineering, 7(3), 71-84.

Quando as metas tanto da produtividade como da qualidade não são atendidas, de imediato à área de engenharia junto ao departamento de planejamento realizam ações para minimizar às perdas ocasionadas pelo atraso gerado, e busca colocar o cronograma em dia. O entrevistado 3, informa que a construtora, faz uso do planejamento do seu estoque por meio de controles diários, desde a entrada do material, armazenamento e saída. Fica disponível diariamente a atualização do estoque para que se possa fazer a compra no tempo viável sem impactos na produtividade. Além disso, a logística interna é bastante discutida entre a equipe de engenharia visando os deslocamentos horizontais e verticais.

No caso do deslocamento horizontal visa-se à distância até o elevador cremalheira de cada torre e local de descarga, e nos materiais içados por grua adequando-se ao seu raio de atendimento, além das questões de previsão de permanência do estoque do material frente ao cronograma dos serviços que serão realizados no local, que por um período servirá de estoque. É apontado que o FVM é muito útil no planejamento e controle do material, pois consegue de imediato identificar se o material atende as políticas de qualidade da construtora, evitando o recebimento caso haja algum problema e/ou defeito. Em contrapartida, o uso do formulário FVS, já favorece a produtividade juntamente com o controle de qualidade, pois por meio dela é possível fazer a liberação apontando as técnicas e condições de qualidade e, consequentemente, conferindo e liberando passo a passo os serviços.

Dessa forma, evita-se retrabalhos, demolição e reparação de serviços, evitando desperdícios. O entrevistado 3, aponta que fez leitura superficial sobre o Lean, mas nunca aprofundou o conhecimento sobre o tema, e informa que o modelo existente atende as necessidades atuais, por essa razão nunca pensou em fazer alterações no sistema de gestão da produção da construtora. O modelo de gestão aplicado pela construtora tem primícias das ferramentas Lean, mesmo não reconhecida e/ou afirmada pelo entrevistado 3, existe a preocupação e aplicação do Lean pela construtora, quando realiza o controle dos estoques das obras, desde as entradas às saídas dos materiais. É feito um monitoramento / acompanhamento para que o estoque seja disponibilizado na hora certa, quantidade certa, qualidade certa, para produção imediata, evitando estoques parados o que favorece o desperdício de utilização de espaço físico do canteiro de obras e, por meio de uma produção puxada evita-se o desperdício de superprodução. Segundo o respondente a logística dentro do canteiro de obras para as atividades de transporte vertical e horizontal, é explorada pela construtora o uso de equipamentos, para que haja de forma mais eficiente o abastecimento rápido por meio do emprego e uso de grua e cremalheira para abastecimento das atividades do campo, o que evita perdas / desperdícios por movimentos e por tempo de espera gerando maior produtividade nos processos.

Para tornar-se mais produtivo o uso de uma grua, a construtoras pode fazer o içamento de aço (pilares, vigas e bitolas de aço) através de mini grua, que tem capacidade máxima de $500 \mathrm{~kg}$, uma lança de seis metros, braço de 9 metros e capacidade de até $3.000 \mathrm{~kg}$, o que possibilita um raio de alcance maior, agregando valor para o processo de abastecimento de materiais (blocos, argamassa, proteções metálicas, entre outros), disponibilizando a cremalheira para outros tipos de transporte que não é possível fazer o içamento de materiais. Com uso dos formulários FVS, é possível evitar desperdícios com potencial humano, mas as vezes acaba ocorrendo e, e a solução é o treinamento constante junto as equipes. O FVM, sendo identificado com perdas / 

construção civil. Brazilian Journal of Production Engineering, 7(3), 71-84.

desperdícios pelos produtos com defeitos, são realizados ensaios para identificar incompatibilidades que são trabalhadas na conferência de lotes. O entrevistado complementa que sempre há aditivos de contratos devidos aos desperdícios ocasionados nas obras, mas os mais favorecidos são os serviços gerais referentes à argamassa e gesso.

O entrevistado 4 apresentou que a construtora C, faz uso de "software" para gestão da empresa, e relatou que essa ferramenta contribui para o gerenciamento e tomada de decisões no dia a dia da organização. O entrevistado mencionou que os mecanismos do "software" UAU, um ERP (Enterprise Resource Planning) interliga todos os dados e processos da construtora sob uma visão geral de todos os usuários, para controle e tomada de decisões. Sobre o controle, o respondente relata que é feito pelo departamento de qualidade junto ao departamento de engenharia de obra, com base na produção do mês sobre as quantidades de funcionários.

O departamento de qualidade avalia os serviços baseados nos procedimentos e informes técnicos da construtora que são feitos a partir da planilha de Excel para depois alimentar o sistema ERP. O entrevistado apresentou o quadro de gestão à vista que faz uso para o controle de todas as atividades, desde os serviços iniciais até à entrega do empreendimento imobiliário, demonstrando todas as etapas que serão realizadas, informando os cenários atuais, manifestando transparência e clareza junto aos envolvidos nos processos. Todavia, por meio do "software" de gestão faz todo o controle e planejamento, solicitação por parte da engenharia de obras, sumarização, análise e compras, com aprovação prévia do financeiro.

Os materiais nas obras são identificados e armazenados de uma forma que favorece o abastecimento dos empreiteiros a fim de gerar maior volume quanto a superprodução, sem ter a necessidade de alto estoques de materiais, ou seja, a construtora mantém o "just in time" e coloca os materiais na hora certa, quantidade e qualidade certas. Outro ponto relatado, é que na maioria das obras, foi identificado desperdícios de materiais quanto aos blocos de concreto e/ou cerâmico e argamassa para revestimento de parede. A identificação do desperdício de materiais ocorreu quando o orçamento de compras desses itens estava sendo maior que o planejado, ou seja, era gerado aditivos constantes para esses fornecedores. Após a identificação, houve uma redução do desperdício, porém mantem-se ainda esses gastos com aditivos, sendo necessário trabalhar com uma margem sobre às incidências dos demais projetos.

O entrevistado 4 tem conhecimento sobre a filosofia Lean e suas ferramentas, mas nunca conseguiu implementar em sua gestão. O respondente relata que com a adoção da filosofia, em especial sobre o objetivo de eliminar desperdícios com base nos 4 P's, do STP, transformariam a cultura da empresa, o que tornaria o processo construtivo mais produtivo, reduzindo perdas / desperdícios de materiais, entre outros e, consequentemente, apresentariam maior produtividade com ganhos financeiros substanciais. O entrevistado apontou a dificuldade de implantação da filosofia Lean no Brasil em razão dos altos custos de treinamento dos colaboradores envolvidos no processo, além dos fornecedores não estarem preparados para atender à demanda da construtora. O entrevistado complementa que para favorecimento da implantação da filosofia Lean, é necessário que toda cadeia produtiva do setor tenha preparação para responder as necessidades de suprimentos, abastecimento, produção, distribuição, suporte e atendimento.

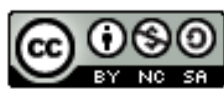




\section{ANÁLISE DE CONTEÚDO}

Bardin (2016), relata que análise de conteúdo é um conjunto de instrumentos metodológicos cada vez mais sutis em constante aperfeiçoamento, que se aplicam a "discursos" (conteúdos e continentes), extremamente diversificados.

\section{APLICAÇÃO DO QUESTIONÁRIO}

\section{(Categoria: Aplicacão de Gestão da Qualidade em canteiro de obras)}

1 - Atualmente é aplicado algum modelo de gestão de qualidade para o canteiro de obra com foco no estoque (materiais), produção e qualidade? Se sim, quais?

2 - Como é feito o controle de produtividade e qualidade das atividades em canteiro de obra? É utilizado algum conceito? Qual o software ou ferramenta que faz uso para o controle?

\section{(Categoria: planejamento)}

3 - Como é feito o planejamento de controle de materiais e produtividade? Alguma ferramenta em específico?

4 - A empresa faz uso do FVS (Ficha de Verificação de Serviço) e FVM (Ficha de Verificação de Materiais)? Você tem conhecimento desse tipo de ferramenta? Comente.

\section{(Categoria: Conhecimento sobre a filosofia "Lean")}

5 - Você tem algum conhecimento sobre Lean Construction (Construção Enxuta) e Lean Thinking (Pensamento Enxuto)? Caso tenha conhecimento, comente!

6 - Sua empresa faz uso do conceito Lean? Se sim, comente sobre quais conceito e/ou ferramentas são aplicados.

\section{(Categoria: Implementar a filosofia "Lean" 4P's)}

7 - Você tem conhecimento sobre o conceito dos 4 P's, com base no Sistema Toyota de Produção (STP)?

8 - Saberia dizer se a empresa aplica de alguma forma os conceitos dos 4 P's, com base no Sistema Toyota de Produção (STP), relacionado a filosofia, processo; pessoas e parceiros e resolução de problemas? Caso seja positivo comente. Caso seja negativo, tem a visibilidade que esta ferramenta poderia contribuir de alguma forma na sua gestão no canteiro de obra junto ao desperdício, qualidade e produção?

\section{(Categoria: Implementar a filosofia "Lean" 14 princípios do STP)}

9 - Você tem conhecimento sobre os 14 princípios com base no Sistema Toyota de Produção (STP)?

10 - Saberia dizer se a empresa aplica de alguma forma os 14 princípios do Lean com base no Sistema Toyota de Produção (STP)? Caso seja positivo comente. Caso seja negativo, tem a visibilidade que esta ferramenta poderia contribuir de alguma forma na sua gestão no canteiro de obra junto ao desperdício, qualidade e produção?

\section{(Categoria: Desperdícios)}

11 - Sobre o seu ponto de vista e vivência no canteiro de obras, qual é o material com maior índice de desperdício?

12 - Com base na sua resposta anterior, por qual motivo este material acaba gerando desperdício no canteiro de obra (pode assinar mais que 1 ):

Falta de mão de obra qualificada

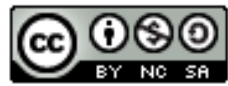


Ausência de orientações técnicas

Superprodução

Tempo de espera

Transporte desnecessário

Processamento

Estoques mal planejados

Potencial humano

Outros

13 - Quanto ao desperdício, como é feito o descarte, existe algum procedimento, há alguma aplicabilidade de gestão sustentável praticado pela empresa voltado para o canteiro de obra? Comente.

\section{(Categoria: Especificar valor ao cliente)}

14 - Pensando na gestão e controle de materiais no canteiro de obra, de alguma forma é aplicado algum conceito abaixo (pode assinar mais que 1):

\section{Conceito $5 \mathrm{~S}$ \\ Just In Time \\ Trabalho Padronizado \\ Controle Visual \\ Total Productive Maintenance \\ Outros}

15 - No seu ponto de vista, o que pode ser criado, implementado ou melhorado para um maior controle afim de evitar desperdício de materiais, atrelado a maior produtividade sem deixar de manter a qualidade nas execuções dos serviços. Comente.

\section{CONCLUSÃO}

Esta pesquisa constatou junto aos entrevistados, que representam as construtoras A, B e C, de forma unânime, à falta de aplicação do "Lean Construction" na gestão da qualidade e prevenção dos desperdícios de materiais nos canteiros de obras. A literatura apresenta que o Lean, pode contribuir para a gestão nos canteiros de obras quando aplicado de maneira bem estruturada e sistematizada, os pressupostos da filosofia. De forma empírica, os respondentes relatam que praticam a gestão, aparentemente, por meio dos processos do Lean, incorporando controles, formulários e procedimentos. Contudo, a falta de conhecimento para a aplicabilidade da filosofia Lean com maior profundidade, tornam-se vulneráveis os processos produtivos pela impossibilidade de rastrear, monitorar e atuar sobre os desperdícios, oriundos dos materiais utilizados nos canteiros das obras. Esses desperdícios obrigam a necessidade de aditivar os contratos que nem sempre são bem-vistos pelos fornecedores. Todavia, o maior responsável pelos desperdícios no geral, é o desperdício do potencial humano e conhecimento da filosofia Lean, que contribuem sobremaneira para as perdas como estoque demasiado, movimentação e transporte desnecessários.

\section{REFERÊNCIAS}

Associação Brasileira de Normas Técnicas [ABNT] (2018). Normas Técnicas. Recuperado de https://www.normastecnicas.com/abnt/o-que-e-abnt/

Ballard, G; Howell, G. (1998). Shielding production: an essential step in production control. Journal of Construction Engineering and Management, 124(1), 11-17.

Bardin, L (2016). Análise de Conteúdo. São Paulo. Edição 70.

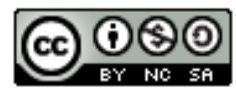



construção civil. Brazilian Journal of Production Engineering, 7(3), 71-84.

Conselho Nacional do Meio Ambiente [CONAMA] (2018). O que é CONAMA. Recuperado de https://www2.mma.gov.br/port/conama/

Câmara Brasileira da Industria da Construção. [CBIC] (2020). Construção civil é a locomotiva do crescimento com emprego e renda. Recuperado de https://cbic.org.br/construcao-civil-e-alocomotiva-do-crescimento-com-emprego-e-renda/

Costa, M. Z. (2018). Estudo de dificuldades para implantação da filosofia lean em empresas construtoras. Monografia para graduação em engenharia civil. Universidade Federal do Rio de Janeiro, Rio de Janeiro, RJ, Brasil.

Gabriel, M. L. D. (2014). Métodos Quantitativos em Ciências Sociais: Sugestões para Elaboração do Relatório de Pesquisa. Desenvolvimento em questão, 12(28): 348-369.

Gerhardt, T. E., Souza, A. C. (2009). In: Gerhardt, T. E., \& Silveira, D. T. Métodos de Pesquisa. 1ed. Série Educação a Distância. Universidade Aberta do Brasil - UAB/UFRGS. Curso de Graduação Tecnológica - Planejamento e Gestão para o Desenvolvimento Rural da SEAD/UFRGS. Editora da UFRGS, Porto Alegre, RS, Brasil.

Gil, A. C. (2002). Como elaborar projetos de pesquisa. $4^{\mathrm{a}}$ ed. Editora Atlas, São Paulo, SP, Brasil.

Gil, A. C. (2010). Como elaborar projetos de pesquisa. $5^{\mathrm{a}}$ ed. Editora Atlas, São Paulo, SP, Brasil.

Gil, A. C. (2008). Métodos e técnicas de pesquisa social. $6^{a}$ ed. Editora Atlas, São Paulo, SP, Brasl.

Grohmann, M. Z. (1998). Redução do desperdício na construção civil: levantamento das medidas utilizadas pelas empresas em Santa Maria. In: Encontro Nacional de Engenharia de Produção, 1998, Niterói. Anais do XVIII Encontro Nacional de Engenharia de Produção.

Koskela, L. (1992). Application of the new production philosophy to construction. CIFE technical report. Stanford University, p.72.

Koskela, L. (2004). Moving on beyond Lean Thinking. Lean Construction Journal, Louisville, CO, Volume 1, Issue 1, p. 24-37.

Lakatos, E. M.; Marconi, M. de A. (2007). Fundamentos de metodologia científica. 6. ed. Editora Atlas, São Paulo, SP, Brasil.

Melo, M. (2012). Gerenciamento de projetos para construção civil. $2^{\mathrm{a}}$ ed. Editora Brasport, Rio de Janeiro, RJ, Brasil.

Miguel, P. A. C. (2007). Case research in production engineering: structure and recommendations for its conduction. Gestão \& Produção, 17(1), 216-229.

International Organization for Standardization [ISO] (2018). ISO 9001: Como aplicar na construção civil. Recuperado de https://www.sienge.com.br/blog/iso-9001-como-aplicar-na$\underline{\text { construcao-civil/ }}$

Plano Brasileiro da Qualidade e Produtividade do Habitat [PBQP-H] (2016). O que é PBQPH. Recuperado de https://certificacaoiso.com.br/pbqp-h/

Piatkowski, M. (2004). Training recommendations for implementing Lean Manufacturing. FSP Consulting Inc.

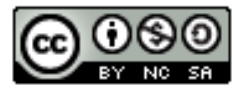



construção civil. Brazilian Journal of Production Engineering, 7(3), 71-84.

Prodanov, C. C., \& Freitas, E. C. (2013). Metodologia do trabalho científico: métodos e técnicas da pesquisa e do trabalho acadêmico. $2^{\text {a }}$ ed. Editora Feevale, Novo Hamburgo, Rio Grande do Sul, Brasil.

Produto Interno Bruto (PIB) (2020). PIB da construção fechará 2020 com queda de 2,5\%, projeta Sinduscon-SP. Recuperado de https://valorinveste.globo.com/mercados/brasil-epolitica/noticia/2020/12/01/pib-da-construcao-fechara-2020-com-queda-de-25percent-projetasinduscon-sp.ghtml

Plano de Gerenciamento de Resíduos Sólidos da Construção Civil (PGRSCC) (2018). Recuperado de http://licenciarambiental.com.br/o-que-e-pgrscc-plano-de-gerenciamento-deresiduos-solidos-da-construcao-civil

Raupp, F.M., \& Beuren, I. M. (2008). Metodologia da Pesquisa Aplicável às Ciências Sociais. p. 76-97. In: Beuren, I. M. Como elaborar trabalhos monográficos em contabilidade. 3 ed. Editora Atlas, São Paulo, SP, Brasil.

Shingo, S. (1996). O Sistema Toyota de Produção do ponto de vista da Engenharia de Produção. Editora Artmed, Porto Alegre, RS, Brasil.

Triviños, A. N. S. (1987). Introdução à pesquisa em ciências sociais: a pesquisa qualitativa em educação. $1^{\mathrm{a}}$ ed. Editora Atlas, São Paulo, SP, Brasil.

Womack, J. P. (2004). Mentalidade enxuta nas empresas: elimine os desperdícios e crie riqueza. $15^{\mathrm{a}}$ ed. Editora Campus, Rio de Janeiro, RJ, Brasil.

Womack, J. P., Jones, D. T., \& Ross, D. (2004). A máquina que mudou o mundo. $13^{\mathrm{a}}$ ed. Editora Campus, Rio de Janeiro, RJ, Brasil.

Zanella, L. C. H. (2011). Metodologia de Pesquisa. $2^{\mathrm{a}}$ ed. Departamento de Ciências da Administração/Universidade Federal de Santa Catarina [UFSC], Florianópolis, SC, Brasil

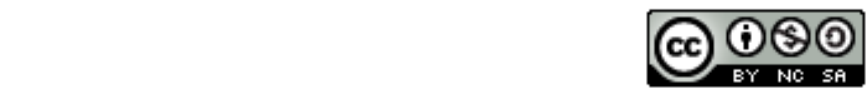

